\title{
PARTICLE FORMATION OF Casearia sylvestris EXTRACT USING A SUPERCRITICAL ANTI-SOLVENT PROCESS
}

\author{
P. BENELLI ${ }^{1}$, S. R. ROSSO COMIM ${ }^{1}$, R. C. PEDROSA ${ }^{2}$, J. V. de OLIVEIRA ${ }^{1}$, S. R. S. \\ FERREIRA $^{1}$
}

${ }^{1}$ Universidade Federal de Santa Catarina, Departamento de Engenharia Química e Engenharia de Alimentos

${ }^{2}$ Universidade Federal de Santa Catarina, Departamento de Bioquímica

E-mail para contato: patybenelli@gmail.com

\begin{abstract}
This research aimed the encapsulation of guaçatonga (Casearia sylvestris) extract in the biopolymer Pluronic F127 by means of supercritical antisolvent (SAS) technique. The system was composed by guaçatonga extract, Pluronic F127, organic solvent (ethanol or ethyl acetate) and supercritical carbon dioxide (CO2). Supercritical C. sylvestris extract was obtained at 50oC, 300 bar and $\mathrm{CO} 2$ flow rate of $8.3 \pm 2 \mathrm{~g} / \mathrm{min}$ added of $5 \%$ (wt/wt) of ethanol, for $3.5 \mathrm{~h}$ of extraction. SAS conditions applied for the encapsulation ranged from 110 to 170 bar at $35 \mathrm{oC}$ and $45 \mathrm{oC}$, based on precipitation tests and on the phase behavior of the system. The morphology of the particles obtained by SAS method and the particle size were characterized by scanning electronic microscopy, being considered as shapeless within the micrometric range. The interaction between the polymer and the encapsulated extract was verified by differential scanning calorimetry indicating that co-precipitated particles were produced.
\end{abstract}

\section{INTRODUCTION}

Casearia sylvestris is a medicinal plant native from Brazil and popularly known as "guaçatonga" and "erva-de-bugre". In folk medicine its leaves are used for skin and oral wound healing and it is also applied as topical anesthetic and antiseptic and anti-ulceration agent (Ferreira et al., 2010; Esteves et al., 2011). Phytochemical investigations revealed that some compounds isolated from this plant present biological potential such as antitumor, cytotoxic, antifungal and anti-inflammatory activities (Oberlies et al., 2002; Oliveira et al., 2009; Santos et al., 2010).

Considering biological attributes, the interest of food and pharmaceutical industries in preserving these properties, by means of protective methods such as coating or encapsulating (inside a carrier agent such as biopolymer), is significantly rising (Reverchon et al., 2000; Jung et al., 2001). Several supercritical fluid-based techniques of micronization and encapsulation, employing mainly $\mathrm{CO}_{2}$, have been proposed in order to obtain solid particles with better control in particle size, size distribution, morphology and crystalline structure, which are difficult to obtain using traditional methods (Reverchon et al., 2003; Franceschi et al., 2008; Michielin et al., 2009). The high pressure technology allows the production of particulated materials preserving the active compounds quality, which is difficult to achieve by traditional techniques due to the presence of organic solvent residues and relatively high 
processing temperatures (Miguel et al., 2008; Varona et al., 2010). Supercritical anti-solvent (SAS) processes can be applied to encapsulate the active substance by simultaneous coprecipitation of the core material (active product) and the carrier (coating film), or to encapsulate the previous formed active particles by suspending it in a carrier solution and then precipitating the carrier by SAS (Cocero et al., 2009).

Optimal operational conditions of pressure and temperature for separation and precipitation processes, such as the SAS technology, are fundamental and can be achieved by the knowledge of the phase behavior of natural extracts in supercritical fluids.

In this context, the aim of present work was to investigate the micronization and encapsulation of the $C$. sylvestris extract and the polymer Pluronic F127 by considering the system phase behavior, using the supercritical anti-solvent (SAS) process. The morphology of particles obtained and an estimation of the particle size were characterized by scanning electronic microscopy (SEM) while the interaction between the polymer and the encapsulated extract was verified by differential scanning calorimetry (DSC).

\section{MATERIAL AND METHODS}

Obtention of $C$. sylvestris extract: The supercritical fluid extraction (SFE) of $C$. sylvestris was accomplished in a dynamic extraction unit previously described by Zetzl et al (2003), with the extraction procedure presented by Michielin et al. (2005). Briefly, the extraction consisted of placing $15 \mathrm{~g}$ of dried and milled material inside the column to form the particles fixed bed, followed by the control of temperature, pressure and solvent flow rate. The extraction was performed and the solute collected in amber flasks and weighted in an analytical balance (OHAUS, Model AS200S, NJ, USA). The SFE assays were performed with $\mathrm{CO}_{2}$ added with ethanol (ETOH) or ethyl acetate (ETOAC) as a co-solvent. The extraction was done at $50{ }^{\circ} \mathrm{C}, 300$ bar and $\mathrm{CO}_{2}$ flow rate of $8.3 \pm 2 \mathrm{~g} / \mathrm{min}$ for $3.5 \mathrm{~h}$ of extraction and using $5 \%(\mathrm{wt} / \mathrm{wt}$ ) of ethanol or ethyl acetate. The SFE assay was performed with $99.9 \%$ pure carbon dioxide, delivered at pressure up to 60 bar (White Martins, Brazil). The resulting mixture from the SFE was separated by using reduced pressure to evaporate the co-solvents in a rotary evaporator (Fisatom, 802, Brazil). The phase equilibrium data which give directions of ideal operational conditions to be applied in the SAS process was obtained in a previous study (Benelli et al., 2014).

Supercritical anti-solvent (SAS) encapsulation: The supercritical encapsulation of Casearia sylvestris extract in Pluronic F127 was performed in a SFE unit adapted to the SAS process as described by Mezzomo et al. (2013). The organic solution was composed by $C$. sylvestris extract $(1: 100, \mathrm{wt} / \mathrm{wt})$ and Pluronic F127 (3:100, wt/wt), both dissolved in ethanol or ethyl acetate, with resulting concentrations of $7.9 \mathrm{mg} / \mathrm{mL}$ and $24 \mathrm{mg} / \mathrm{mL}$ for the extract and polymer, respectively. Ethanol and ethyl acetate was chosen due to the high solubility of the extract and polymer. The precipitation conditions applied were pressures of 90, 130 and 170 bar at temperature of $35{ }^{\circ} \mathrm{C}$ and 110,140 and 170 bar at temperature of $45{ }^{\circ} \mathrm{C}$, organic solution flow rate of $1.0 \mathrm{~mL} / \mathrm{min}$, and constant $\mathrm{CO}_{2}$ flow rate of $8.43 \mathrm{~L} / \mathrm{min}$. The conditions applied were selected based on preliminary precipitation tests and also on previous results of the group and on the phase behavior of the multicomponent system $(C$. sylvestris extract + ethanol or ethyl acetate $+\mathrm{CO}_{2}$ ), studied by Benelli et al. (2014). The pressures values tested remain near and above the mixture critical pressure of the mixture for the temperature of 35 
and $45{ }^{\circ} \mathrm{C}$. The $\mathrm{CO}_{2}$ flow rate was chosen with the aim of promoting an intense mixing between the solution (extract + solvent) and the anti-solvent inside the precipitation cell, performed at a $\mathrm{CO}^{2}$ mass fraction of $95 \%(\mathrm{wt} / \mathrm{wt})$. The precipitation experiments started by fulfilling the precipitator vessel with pure $\mathrm{CO}_{2}$ and, when the desired operating conditions (temperature, pressure and $\mathrm{CO}_{2}$ flow rate) were achieved and remained stable, $10 \mathrm{~mL}$ of pure organic solvent (ethanol or ethyl acetate) was feed into the chamber until the system reached the equilibrium. After that, $30 \mathrm{~mL}$ of organic solution (extract + polymer + organic solvent) was pumped, by HPLC pump, inside the precipitator followed by pure $\mathrm{CO}_{2}$ pumped inside the cell during 15 minutes in order to guarantee total drying of the particles. The quantity of organic solution used enabled the collection of sufficient amount of precipitated powder for analysis. The precipitation chamber was slowly depressurized to atmospheric pressure and, subsequent to the decompression, the sample of precipitated particles retained in the filter was collected for the particle analysis. All samples were stored at temperatures of $-18{ }^{\circ} \mathrm{C}$ and protected from light to avoid the decomposition of the product (Mezzomo et al., 2012).

Particle morphology and estimated size: The samples of the powder collected from the precipitator were analyzed by scanning electronic microscopy (SEM) (JSM 6390LV-JEOL, USA). A gold sputter was used to cover the samples with a thin layer of gold to allow the light reflection for particle evaluation. An estimation of the mean particle size was measured by ZEISS Image Analysis Software. This procedure was performed according to recently described by Mezzomo et al. (2012).

DSC characterization of resultant particles and pure extract: Thermal analyses of the precipitated samples and the $C$. sylvestris extract were performed by differential scanning calorimetry (DSC) (Jade DSC - Perkin Elmer, USA), analyzed as presented by Benelli et al. (2014) Briefly, the samples were analyzed under nitrogen atmosphere for temperatures between -20 and $200{ }^{\circ} \mathrm{C}$ with a heating rate of $10{ }^{\circ} \mathrm{C} / \mathrm{min}$. DSC analyses were conducted in order to give information about the interaction between the carrier (polymer Pluronic F127) and the encapsulated material (C. sylvestris extract), and also to estimate modifications of the composition, crystallinity degree and melting temperature caused by the SAS process.

\section{RESULTS AND DISCUSSION}

The results from the scanning electronic microscopy (SEM) of non-precipitated Pluronic F127 and pure Pluronic F127 precipitated at 140 bar and $45{ }^{\circ} \mathrm{C}$, using ethanol or ethyl acetate as organic solvent, and constant values of solution concentration and anti-solvent flow rate are presented in Figure 1.

The results from the SAS process applied, presented in Figure 1, was able to reduce the particle size of pure Pluronic F127 from $612 \pm 162 \mu \mathrm{m}$ to $546 \pm 90 \mu \mathrm{m}$ and $267 \pm 40 \mu \mathrm{m}$, using ethanol and ethyl acetate at 140 bar and $45{ }^{\circ} \mathrm{C}$, respectively. The SEM micrographs indicate that the precipitated particles can be considered shapeless.

The SEM results of precipitated particles obtained at 90, 130 and 170 bar at temperature of $35{ }^{\circ} \mathrm{C}$ and 110,140 and 170 bar at temperature of $45{ }^{\circ} \mathrm{C}$ and constant values of solution concentration and anti-solvent flow rate are presented in Figure 2 and Figure 3, using ethanol and ethyl acetate as organic solvent, respectively. The SEM micrographs indicate that the 
129

precipitated particles can be considered shapeless, and the particles size for the samples produced at all conditions tested were within the micrometric range.

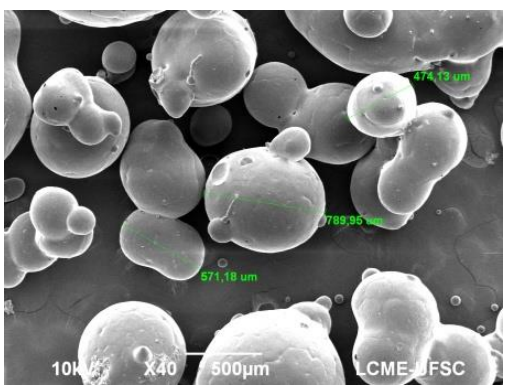

(a)

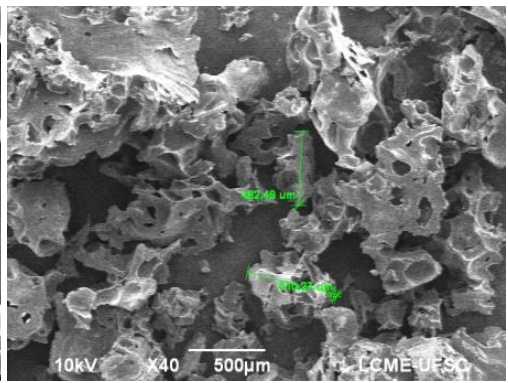

(b)

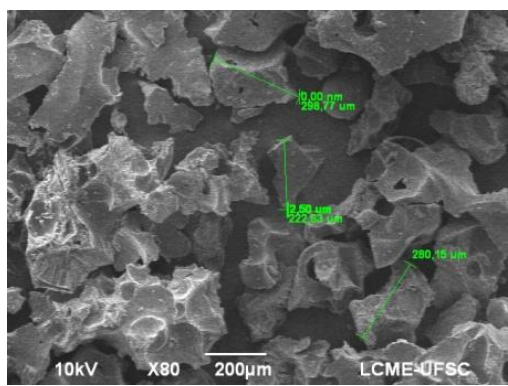

(c)

Figure 1 - Electronic micrographs obtained by scanning electronic microscopy (SEM) and their respective particle size of pure Pluronic F127 samples of $(a)$ non-precipitated $(612 \pm 162 \mu \mathrm{m})$ and precipitated by supercritical anti-solvent (SAS) process at 140 bar ant $45^{\circ} \mathrm{C}$ using $(b)$ ethanol as organic solvent $(546 \pm 90 \mu \mathrm{m})$ and $(c)$ ethyl acetate as organic solvent at $(267 \pm 40 \mu \mathrm{m})$.

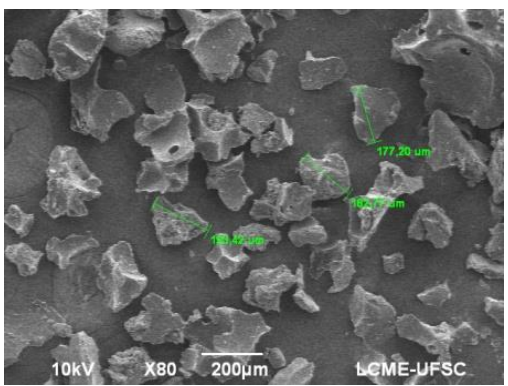

(a)

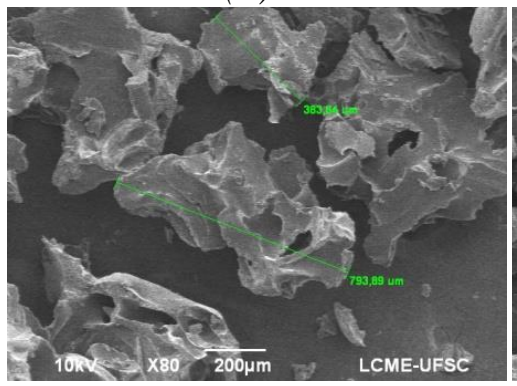

(d)

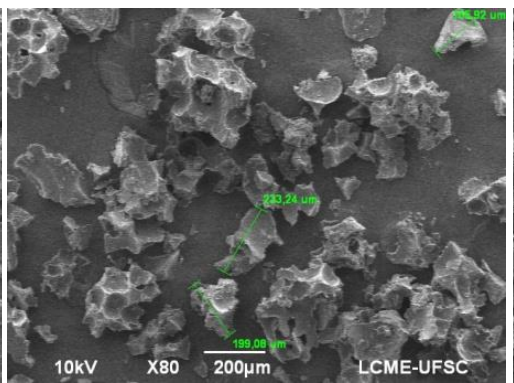

(b)

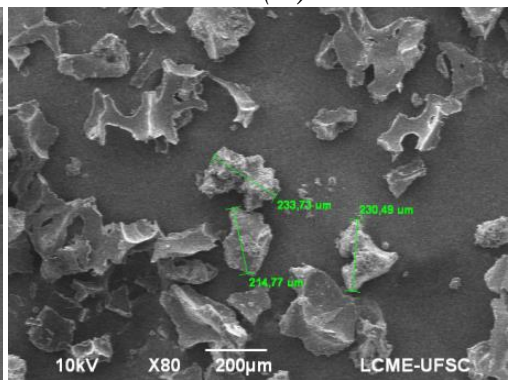

(e)

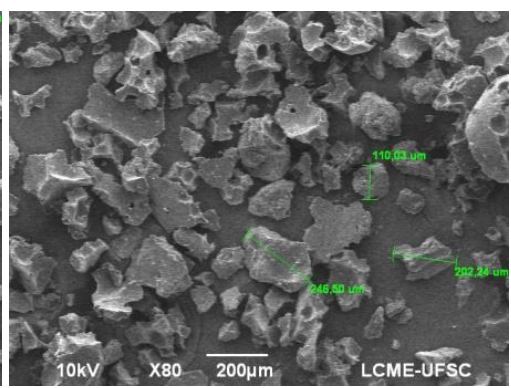

(c)

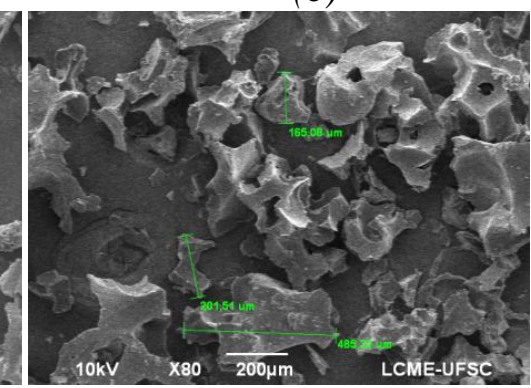

$(f)$

Figure 2 - Electronic micrographs obtained by scanning electronic microscopy (SEM) of precipitated samples by supercritical anti-solvent (SAS) process and their respective particle size using ethanol as organic solvent: (a) 90 bar and $35^{\circ} \mathrm{C}(184 \pm 8 \mu \mathrm{m})$; (b) 130 bar and $35^{\circ} \mathrm{C}(196 \pm 39 \mu \mathrm{m}) ;$ (c) 170 bar and $35^{\circ} \mathrm{C}(186 \pm 70 \mu \mathrm{m}) ;(d) 110$ bar and $45^{\circ} \mathrm{C}(589 \pm 290 \mu \mathrm{m}) ;(e) 140$ bar and $45^{\circ} \mathrm{C}(224 \pm 13 \mu \mathrm{m})$; (f) 170 bar and $45^{\circ} \mathrm{C}(183 \pm 26 \mu \mathrm{m})$.

Considering the results presented in Figures 2 and 3, the temperature effect on the particles aspects was also observed by the particle size results, i.e., larger particles were obtained at the temperature of $45{ }^{\circ} \mathrm{C}$ compared to the ones produced at $35{ }^{\circ} \mathrm{C}$. Also, the particles obtained using ethanol as organic solvent at $35^{\circ} \mathrm{C}$ (Figure 1) did not present pressure effect on the estimated particle size, instead of $45{ }^{\circ} \mathrm{C}$, where the increase in pressure reduced the particle size. Analyzing the particles size obtained using ethyl acetate as organic solution, the pressure effect was observed for the temperature of $35^{\circ} \mathrm{C}$, where the particle size was reduced with the increase in pressure. This behavior was not observed at $45^{\circ} \mathrm{C}$, indicating that 
156

157

158

159

160

161

162

163

164

165

166

167

168

169

170

171

172

173

174

175

176

177

178

179

180

181

182

183

184

185

186

187

188

this temperature was not suitable to precipitation process with ethyl acetate because the high particle size produced.

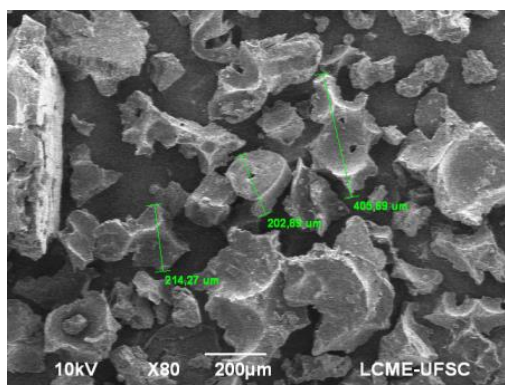

(a)

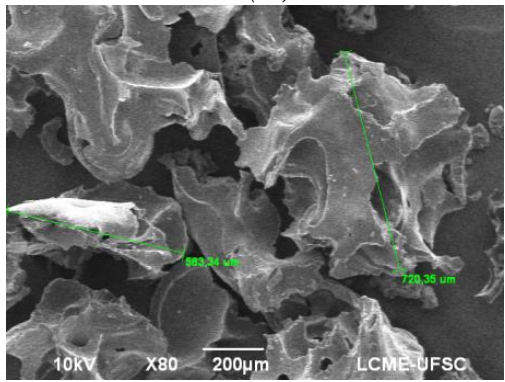

(d)

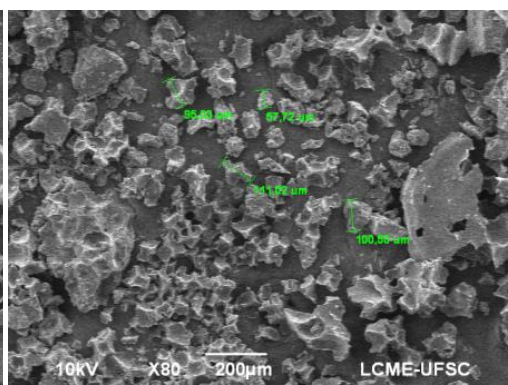

(b)

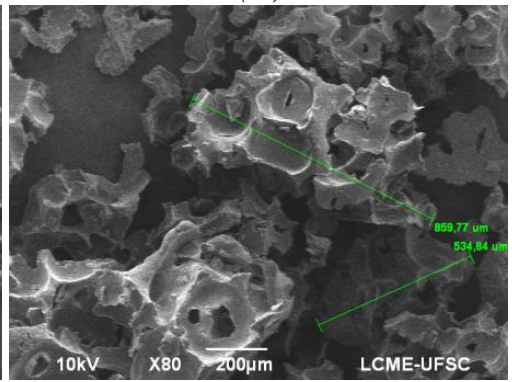

(e)

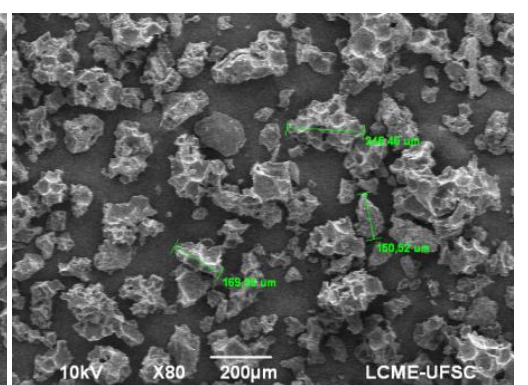

(c)

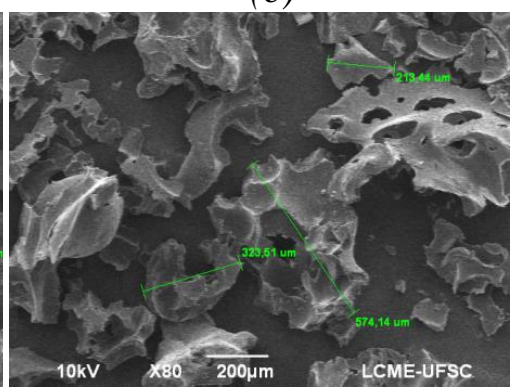

(f)

Figure 3 - Electronic micrographs obtained by scanning electronic microscopy (SEM) of precipitated samples by supercritical anti-solvent (SAS) process and their respective particle size using ethyl acetate as organic solvent: (a) 90 bar and $35^{\circ} \mathrm{C}(274 \pm 114 \mu \mathrm{m})$; (b) 130 bar and $35^{\circ} \mathrm{C}(102 \pm 8 \mu \mathrm{m})$; (c) 170 bar and $35^{\circ} \mathrm{C}(188 \pm 50 \mu \mathrm{m}) ;(d) 110$ bar and $45^{\circ} \mathrm{C}(652 \pm 97 \mu \mathrm{m}) ;(e) 140$ bar and $45^{\circ} \mathrm{C}(697$ $\pm 230 \mu \mathrm{m}) ;(f) 170$ bar and $45^{\circ} \mathrm{C}(394 \pm 255 \mu \mathrm{m})$.

Regarding the particles morphology in Figures 2 and 3, all samples obtained at different pressure conditions and type of organic solvent used (ethanol or ethyl acetate) were shapeless and therefore the pressure effect on particles form was not detected within the range of conditions studied. The same behavior was also reported by Franceschi et al. (2008), in the precipitation of $\beta$-carotene and PHBV and co-precipitation from SEDS (Solution-Enhanced Dispersion) process using supercritical $\mathrm{CO}_{2}$.

The DSC results for the SAS samples are observed in Figures 4 and 5, which also presents the heating curves for the pure non-precipitated polymer (Pluronic F127) and for the C. sylvestris extract.

The DSC heating curves, Figures 4 and 5, showed all SAS samples analyzed. The pure polymer showed one band at near $60{ }^{\circ} \mathrm{C}$, while the $C$. sylvestris extract show no band at the heating curve. The $60{ }^{\circ} \mathrm{C}$ peak for the SAS heating curves are probably related to the polymer melting point because the heating curve for the non-precipitated polymer indicate a melting point near $55^{\circ} \mathrm{C}$ (Mezzomo et al., 2012). Regarding the processed samples, the DSC results show a slightly decrease in the fusion/melting temperature (from 60 to near $55^{\circ} \mathrm{C}$ ) and also in the enthalpy of fusion, compared to the non-precipitated Pluronic F127. This result may be due to the decrease in the polymer crystallinity with the SAS precipitation or to a partial modification in the crystalline form of the Pluronic F127 during the recrystallization process. Also, the incorporation of the extract inside the polymer (co-precipitation) may be detected by the absence of the crystalline and melting peaks of the active substance, which are normally 
observed when the active component is not coated by the polymer. Some extracts have no characteristic peak detectable, but only variations on the heat flow in the DSC analysis (Mezzomo et al., 2012; Cocero et al., 2009).

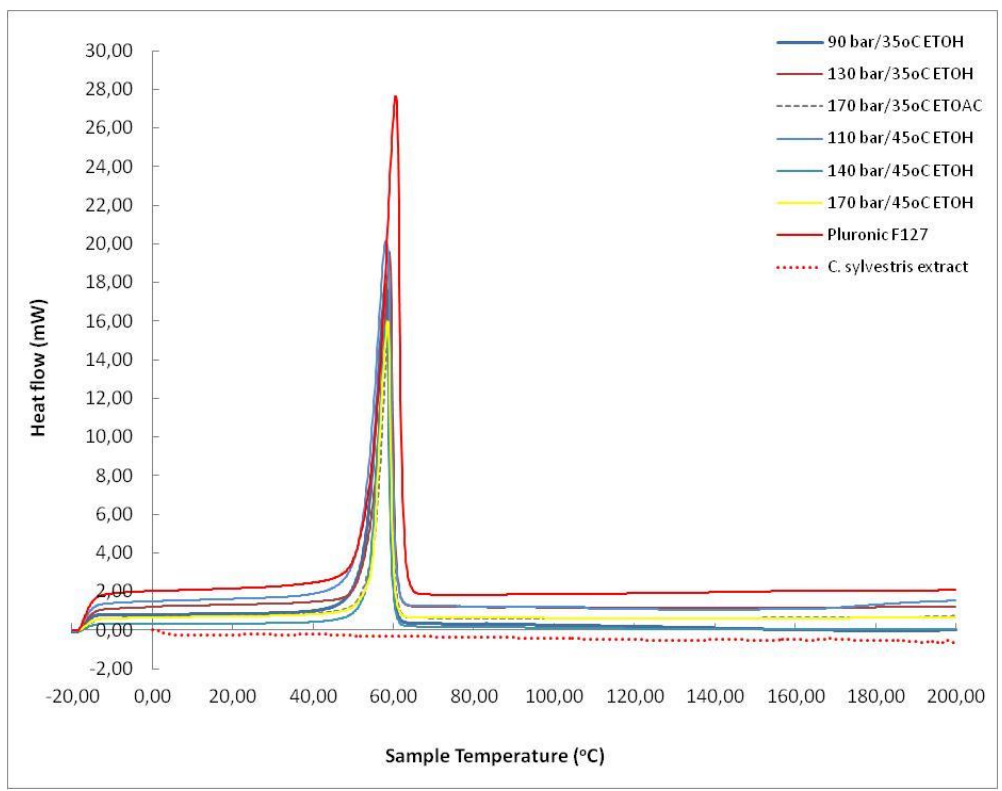

Figure 4 - Differential scanning calorimetry (DSC) analysis obtained for pure polymer (Pluronic F127), Casearia sylvestris extract and precipitated samples obtained by SAS process using ethanol as co-solvent at $35^{\circ} \mathrm{C}$ and $45^{\circ} \mathrm{C}$.

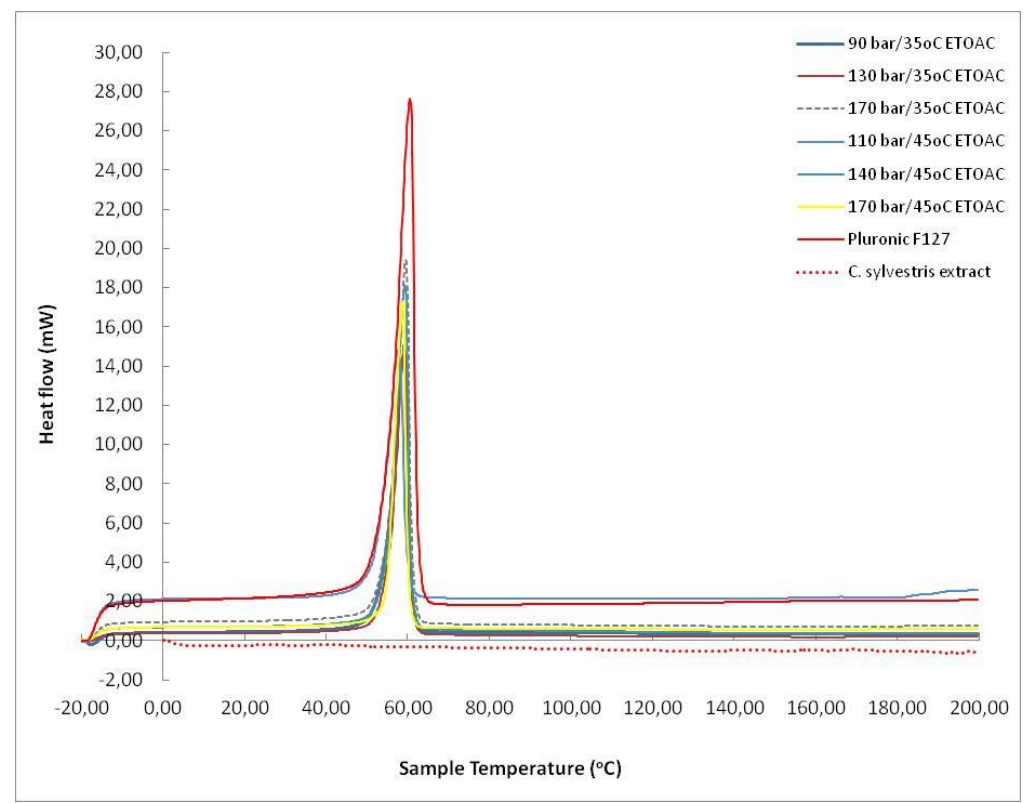

Figure 5 - Differential scanning calorimetry (DSC) analysis obtained for pure polymer (Pluronic F127), Casearia sylvestris extract and precipitated samples obtained by SAS process using ethyl acetate as co-solvent at $35{ }^{\circ} \mathrm{C}$ and $45^{\circ} \mathrm{C}$.

Finally, according to the results for SAS samples and with the absence of heat flow variations - characteristic from C. sylvestris extract - (DSC results), it is suggested that 
encapsulation occurred, i.e., the active substance was incorporated into the carrier matrix (Pluronic F127).

\section{CONCLUSIONS}

SAS process employed to $C$. sylvestris extract was successfully applied to its encapsulation in Pluronic F127, producing micro-particles at all SAS conditions performed. Some operational conditions applied produced particles with smaller size (micrometric order) and better size uniformity, when compared to non-precipitated polymer.

Further studies about the co-precipitation of C. sylvestris extract and Pluronic F127, including encapsulation efficiency and encapsulation loading are fundamental to define adequate conditions for the particles production by means of supercritical fluid methods.

\section{Acknowledgements}

The authors wish to thank CNPq for the doctoral fellowship (Process 142226/2010-6) and financial support, Brazervas Laboratório Fitoterápico Ltda. for the raw material supply. Also, special thanks to PROFI-UFSC and LCME-UFSC for their technical support.

\section{REFERENCES}

Benelli, P.; Rosso-Comim, S. R.; Oliveira, J. V.; Pedrosa, R. C.; Ferreira, S. R. S. Phase equilibrium data of guac, atonga (Casearia sylvestris)extract + ethanol + CO2system and encapsulation using a supercriticalanti-solvent process. J. Supercrit. Fluids, 2014, http://dx.doi.org/10.1016/j.supflu.2014.02.007, In press.

Cocero, M. J.; Martín, Á; Mattea, F.; Varona, S. Encapsulation and co-precipitation processes with supercritical fluids: Fundamentals and applications, J. Supercrit. Fluids, v. 47, p. 546$555,2009$.

Esteves, I.; Lima, L. M.; Silva, M. L.; Santos, L. S.; Rodrigues, M.; Silva, J. M. S.; Perazzo, F. F.; Carvalho, J. C. T. Casearia sylvestris $\mathrm{Sw}$ essential oil activity in inflammation in rats induced Bybothrops alternatus venom, Int. J. Pharm. Sci. Ver. Res., v. 7(2), p. 28-32, 2011.

Ferreira, P. M. P.; Santos, A. G.; Tininis, A. G.; Costa, P. M.; Cavalheiro, A. J.; Bolzani, V. S.; Moraes, M. O.; Costa-Lotufo, L. V.; Montenegro, R. C.; Pessoa, C. Casearin X exhibits cytotoxic effects in leukemia cells triggered by apoptosis, Chem.-Biol. Interactions, v. 188, p. 497-504, 2010.

Franceschi, E.; Kunita, M. H.; Tres, M. V.; Rubira, A. F.; Muniz, E. C.; Corazza, M. L.; Dariva, C.; Ferreira, S. R. S.; Oliveira, J. V. Phase behavior and process parameters effects on the characteristics of precipitated theophylline using carbon dioxide as antisolvent, $J$. Supercrit. Fluids, v. 44, p. 8-20, 2008.

Jung, J.; Perrut, M. Particle design using supercritical fluids, J. Supercrit. Fluids, v. 20, p. 179-219, 2001.

Mezzomo, N.; Paz, E.; Maraschin, M.; Martín, Á.; Cocero, M. J.; Ferreira,S. R. S. Supercritical anti-solvent precipitation of carotenoid fraction from pink shrimp residue: Effect 
of operational conditions on encapsulation efficiency, J. Supercritical Fluids, v. 66, p. 342349, 2012.

Mezzomo, N.; Ferreira, S. R. S.; Supercritical anti-solvent precipitation of sodium ibuprofen. In: I. Mejía, E. Sánchez, C. Pardo, J. A. García (Eds.), Proceedings of III Iberoamerican Conference on Supercritical Fluids, 01-05 April, 2013, Cartagena de Indias (Colombia), Applied Thermodynamics and Supercritical Fluids Group, School of Chemical Engineering, Universidad del Valle Cali, 2013.

Michielin, E. M. Z.; Bresciani, 1. F. V.; Danielski, 1.; Yunes, R. A.; Ferreira, S. R. S. Composition profile of horsetail (Equisetum giganteum L.) oleoresin: comparing SFE and organic solvents extraction. J. of Supercrit. Fluids, v. 33, p. 131-138, 2005.

Michielin, E. M. Z.; Rosso, S. R.; Franceschi, E.; Borges, G. R.; Corazza, M. L.; Oliveira, J. V.; Ferreira, S. R. S.; High-pressure phase equilibrium data for systems with carbon dioxide, $\alpha$-humulene and trans-caryophyllene, J. Chem. Thermodyn., v. 41, p. 130-137, 2009.

Miguel, F.; Martín, Á.; Mattea, F.; Cocero, M. J. Precipitation of lutein and co-precipitation of lutein and poly-lactic acid with the supercritical anti-solvent process, Chem. Eng. Process., v. 47, p. 1594-1602, 2008.

Oberlies, N. H.; Burgess, J. P.; Navarro, H. A.; Pinos, R. E.; Fairchild, C. R.; Peterson, R. W.; Soejarto, D. D.; Farnsworth, N. R.; Kinghorn, A. D.; Wani, M. C.; Wall, M. E. Novel bioactive clerodane diterpenoids from the leaves and twigs of Casearia sylvestris, J. Nat. Prod., v. 65(2), p. 95-99, 2002.

Oliveira, A. M.; Santos, A.G.; Santos, R. A.; Csipak, A. R.; Olivato, C.; Silva, I. C.; Freitas, M. B.; Bassi, C. L.; Cavalheiro, A. J.; Bolzani, V. S.; Silva, D. H. S.; Sakamoto-Hojo, E. T.; Takahashi, C. S.; Soares, C. P. Ethanolic extract of Casearia sylvestris and its clerodane diterpen (caseargrewiin F) protect against DNA damage at low concentrations and cause DNA damage at high concentrations in mice's blood cells, Mutagenesis, v. 24( 6), p. 501-506, 2009.

Reverchon, E.; Della Porta, G.; Falivene, M.G.; Process parameters and morphology in amoxicillin micro and submicro particles generation by supercritical antisolvent precipitation, J. Supercrit. Fluids, v. 17, p. 239-48, 2000.

Reverchon, E.; De Marco, I.; Caputo, G.; Della Porta, G. Pilot scale micronization of amoxicillin by supercritical antisolvent precipitation, J. Supercrit. Fluids, v. 26, p. 1-7, 2003.

Santos, A. G.; Ferreira, P. M. P.; Júnior, G. M. V.; Perez, C. C.; Tininis, A. G.; Silva, G. H.; Bolzani, V. S.; Costa-Lotufo, L. V.; Pessoa, C.; Cavalheiro, A. J. Casearin X, its degradation product and other clerodane diterpenes from leaves of Casearia sylvestris: evaluation of cytotoxicity against normal and tumor human cells, Chem. Biodivers., v. 7, p. 205-215, 2010.

Varona, S.; Kareth, S.; Martín, Á.; Cocero, M. J. Formulation of lavandin essential oil with biopolymers by PGSS for application as biocide in ecological agriculture, J. Supercrit. Fluids, v. 54, p. 369-377, 2010.

Zetzl, C.; Lozano, G. A.; Brunner, G. Compilation of batch SFE-Models for natural products. In: I Iberoamerican Conference on Supercritical Fluids (PROSCIBA). Foz do Iguaçu, Paraná, Caderno de Resumos do PROSCIBA, 2007. 